THE DEVELOPMENT OF A MEDICINE 
In all experimental knowledge there are three phases : An observation is made, a comparison is established and a judgment rendered.

\section{Bernard (1865)}

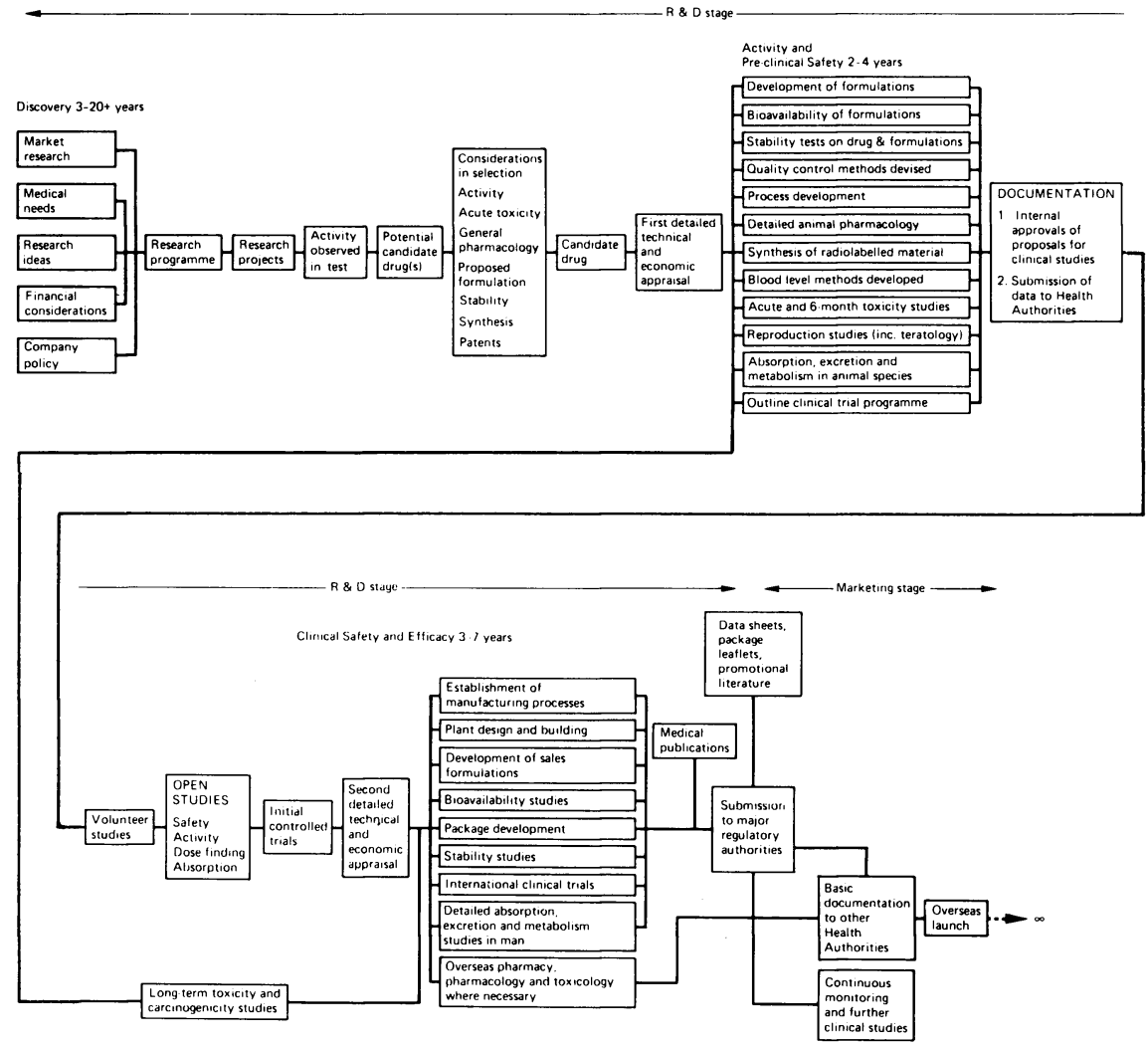

Stages in the discovery and development of a typical drug (courtesy ICI and the Financial Times). 


\title{
THE DEVELOPMENT OF A
}

MEDICINE

\author{
R. B. Smith
}

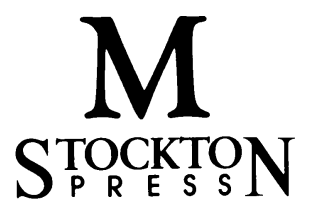


All rights reserved. No reproduction, copy or transmission of this publication may be made without written permission.

No paragraph of this publication may be reproduced, copied or transmitted save with written permission or in accordance with the provisions of the Copyright Act 1956 (as amended).

Any person who does any unauthorised act in relation to this publication may be liable to criminal prosecution and civil claims for damages.

First published 1985

Published in the United Kingdom by

THE MACMILLAN PRESS LTD

Houndmills, Basingstoke, Hampshire RG21 2XS

and London

Companies and representatives

throughout the world

British Library Cataloguing in Publication Data

Smith, Richard B.

The development of a medicine.

1. Pharmacology

I. Title

615'.1 RM300

ISBN 978-0-333-36885-5 ISBN 978-1-349-17954-1 (eBook)

DOI 10.1007/978-1-349-17954-1

Published in the United States and Canada by

Stockton Press

15 East 26th Street, New York, NY 10010

Library of Congress Cataloging in Publication Data

Smith, R. B. (Richard Barry), 1940-

The development of a medicine.

1. Pharmacy. 2. Pharmacy-Research. 3. DrugsTesting. 4. Drug trade. I. Title. [DNLM: 1. Clinical Trials. 2. Drug Evaluation. 3. Drug Industry.

4. Research. QV 771 S657d]

$\begin{array}{llll}\text { RS92.S63 } & 1985 & 615 \% .7 & 85-4780\end{array}$

ISBN 978-0-943818-09-2

To Stephanie, Edward, Alexander and William 


\section{Contents}

Foreword

Preface

Acknowledgments

1 INTRODUCTION

Definition of the stages of drug development with comment on the ever-increasing cost and lengthening timescale.

Development consists of both integrated and non-sequential courses of events

2

DISCOVERY

Initially purely empirical - alcohol, cocaine and opium.

Later, the recognition of scurvy and treatment of malaria was achieved. Identification of syntheses. Appreciation of beneficial effects of aspirin and digitalis. Ehrlich's discovery and the theory of specificity. The antibacterial war sulpha drugs, penicillin, streptomycin and cephalosporins. The identification of natural effector substances and the usage of extracts - insulin, etc. Selye's influence - steroids and later synthetic non-steroidal anti-inflammatory agents. Alquist and the receptor theory - beta blockade. Developments in therapy for mental disease - tranquillisers, anxiolytics, hypnotics. $\mathrm{H}_{2}$ receptor antagonism. Analgesia

3 BASIC SCIENTIFIC CHARACTERISATION

Chemical

Initially ideas from vegetable extracts and synthesis, followed by animal pharmacology studies giving clues to 
alternative synthetic substances. 'Molecular roulette' synthesis. Early animal testing. Pilot batch manufacture. Establishment of specifications. Scale-up. The assurance of quantity and quality of the material

\section{Biological}

Pharmacological investigations into primary and secondary effects in animals and organ systems in both normal and abnormal models. Isolated-organ work. Intention and aspiration to give predictability of effects in man. Studies of absorption, distribution, metabolism and excretion in animals after single and multiple dosing

Build-up of knowledge from LD 50 studies through 7-day, 3-month and 12-month toxicity studies in a number of different species. Fertility testing, peri- and post-natal studies. Teratology, mutagenicity and carcinogenicity testing

Development of various types of injections, and irritation studies. Advantages and disadvantages of different tablet and capsule presentations. Common problems with some formulations. Sugar coating and film coating. Syrups, suspensions, ointments, creams, suppositories, pessaries, implants, powders and aerosols, etc. Stability testing. Product security and child safety

Volunteer studies. Human pharmacokinetics - absorption, distribution, metabolism and excretion studies. Preparation of volunteers and conduct of trials. Dose-effect relationships. Steady-state kinetics. Single- and multiple-dosage investigations. Bioavailability studies - alternate formulations. Special investigations. Discussion of true and false positives and negatives in both pharmacology and toxicology 
Definition of clinical studies. Programme to establish indications for use, dosage range in different situations, method of usage - dosage increments. Side actions both good and bad, attempts to quantify and qualify with degrees of severity. Interactions. Studies in different populations including both the young and the old. Null hypothesis and different types of trial design. Informed consent. Protocol design and development. Patient record forms. Confidentiality. Risk-benefit ratio

Different concerns of different regulatory authorities. USA drug lag. History of regulatory development from quality assurance to safety, efficacy and latterly utility. Clinical trial and full-marketing licences. Harmonisation of regulations. Quality assurance of data

9 MARKETING

Importance of early involvement. Product management. Market research and development of product profile. Sales teams, launches. Pre- and post-marketing utilisation trials. Promotional material

10 PROJECT CO-ORDINATION

Project portfolio and mix of short-, medium- and long-term projects. Project management as a separate discipline operating as a matrix across line disciplines. Critical-path analysis. Planning and monitoring

Problems of scale-up from bench to pilot plant to largescale manufacture of both the fine chemical and the formulated product. Contract manufacture. Pack development. Line integrity and good manufacturing practice 
Wider usage with launch in a number of markets. Expansion of patient population. Definition of adverse effects and adverse-effect monitoring by spontaneous reporting and post-marketing surveillance. Quantitative and qualitative parameters. Further definition of risk-benefit ratio. Comparative medications, drug interactions and compatibilities. Over-use, misuse and abuse. Formulation changes and development of indications

13 INTERNATIONAL DEVELOPMENT

Simultaneous registration applications. Patents, trademarks. Cross-licensing arrangements. The management of great amounts of information by specialists. Computer storage and retrieval. Data editing and statistical analysis

14 RISK-BENEFIT RATIO

Discussion of role of government in attempting to diminish risk. Possibility of denying patients access to specific drugs. Impossibility of totally accurate prediction of adverse effects either qualitative or quantitative

15 INTEGRATION AND INNOVATION

International contacts and dialogue both externally and internally within companies. Circus movement of knowledge and ideas

16 THE ORGANISATION

Interlocking of project and product management within a central organisation. Peripheral extensions of a central organisation. Importance of good communication. Importance of different organisational disciplines 
17 THE FUTURE

Research into 'western diseases'. Orphan drugs. The futility of search for absolute safety. The problems of toxicological research highlighted. Importance of human pharmacology. Benefits to patients

Index 


\section{Foreword}

Medicines, and the drugs they contain, are taken for granted by most people. We have been born and bred in a generation whose medicine cabinets contain 'something for every occasion' - analgesics for pain, antacids for indigestion, laxatives for constipation, contraceptives, and, all too often, antidepressants, tranquillisers and sleeping pills. So conditioned have we become to thinking that 'there is a pill for every problem' that many of us forget the equally important truism 'every pill has its problem and its price'.

The price of a drug is not only the enormous cost of its development, assessment and marketing, but also the sum of adverse effects which it may inflict, and which have to be accepted by the few if its beneficial effects are to be enjoyed by the many. We cannot be reminded too often of this risk-benefit ratio which every therapeutically active medicine possesses, and in this book Dr Smith spells out the situation clearly and concisely, based on his long experience in drug development.

An understanding of the processes that lead to the discovery of new medicines and the balanced assessment of their therapeutic roles may lead to a better appreciation of their true value and a more responsible approach to their use. This is essential if the true potential of drug treatment is to be realised in the conquest of disease.

Paul Turner

Professor of Clinical Pharmacology

St Bartholomew's Hospital

London, ECl 


\section{Preface}

This book has been in gestation for almost five years. During this time I have been made aware repeatedly of the fact that, although many people do have a genuine interest in how their medicines come into being, relatively few have an overall view on how this development of a medicine is achieved. Therefore the major purpose of this book is to provide a general 'broad-brush' impression of the many components of drug development. It aims to draw together and associate the various disciplines which interrelate and interact to make the end result - a safe and effective medicine for human use - a reality. 


\section{Acknowledgments}

I would like to record my sincere thanks to the many friends, both in 'academia' and industry, who, by their advice and encouragement have helped me in writing this book. My especial thanks are due also to Dr Eric Cliffe, Dr Desmond Fitzgerald and Professor Kenneth Bentley who have given their time to render essential practical assistance by providing significant amounts of illustrative material, and to Mrs M. J. Wyburn-Mason for kind permission to use part of illustration number 24a from The Causation of Rheumatoid Disease and Many Human Cancers. The Royal Society of Medicine has also been most helpful in locating and photographing illustrative material.

I am extremely grateful for the forbearance, patience and accuracy of Sarah Tobitt and Carol Miller who typed the manuscript through its various drafts and revisions. 